\title{
A dimensão espacial dos conflitos trabalhistas no Nordeste açucareiro: repensando os limites da Justiça do Trabalho na plantation (Pernambuco, século XX)
}

The spatial dimension of labor conflicts in the sugar cane area: rethinking the limits of Labor Judiciary in plantation (Pernambuco/ Northeast/Brazil, 20 ${ }^{\text {th }}$ century)

José Marcelo Marques Ferreira Filho*

Universidade Federal Rural de Pernambuco (UFRPE), Recife, PE, Brasil

\begin{abstract}
RESUMO: O objetivo central deste artigo é defender a ideia de que somente decompondo o espaço - elevando em consideração suas dimensões física, estrutural e sócio-histórica - é possível compreender os limites da Justiça do Trabalho na plantation açucareira no nordeste do Brasil. Baseado numa análise que cruza referenciais da literatura e relatórios oficiais do governo com processos trabalhistas e dados cartográficos, ele discute, numa perspectiva histórica, o papel do domínio territorial exercido pela classe patronal na organização da sociedade açucareira em Pernambuco na segunda metade do século XX. Portanto, neste texto, o espaço exerce um papel de extrema relevância na análise social.
\end{abstract}

PALAVRAS-CHAVE: Espaço. Trabalhadores rurais. Justiça do Trabalho. Zona canavieira de Pernambuco. Plantation.

\begin{abstract}
The main objective of this article is to argue the idea that only by decomposing space - and taking into account its physical, structural and socio-historical dimensions - is possible to understand the limits of Labor Judiciary in the sugar plantation of Northeastern Brazil. Based on an analysis that uses literature and official government reports with labour court documents and public cartographic data, the article debate in a historical perspective about the role of the territorial domain exercised by the employers, in the organization of the sugar society in Pernambuco, during the second half of the $20^{\text {th }}$ century. Therefore, in this text, space plays an extremely relevant role in social analysis.
\end{abstract}

KEYWORDS: Space. Rural workers. Labor Judiciary. Sugar cane area in Pernambuco (Northeast, Brazil). Plantation.

\footnotetext{
* Professor da Universidade Federal Rural de Pernambuco (UFRPE), Recife, PE, Brasil. Doutor em História pela Universidade Federal de Pernambuco (UFPE). E-mail: jmmhistoria@gmail.com.

Orcid: http://orcid.org/0000-0001-6787-0826.
} 
Os embates de classe na Justiça do Trabalho têm sido objeto de análise de vários pesquisadores do Brasil. Diversos projetos de preservação de acervos e da memória da história social do trabalho têm alavancado a produção acadêmica sobre o assunto. Os conflitos trabalhistas na zona rural, contudo, carecem ainda de debates e apreciações mais problematizantes por parte da chamada historiografia nacional. Em Pernambuco, diferentes pesquisas ${ }^{1}$ com base nos arquivos do Tribunal Regional do Trabalho (TRT 6a Região) têm ampliado nosso entendimento sobre as condiçóes de vida dos trabalhadores na plantation açucareira; sobre os perfis dos reclamantes; os direitos por eles reclamados; o funcionamento das Juntas de Conciliação e Julgamento (JCJ) etc. Nenhum deles, entretanto, ao menos de maneira consciente, considera o papel preponderante da dimensão espacial e geográfica na compreensão dos conflitos trabalhistas no mundo do açúcar.

O objetivo central deste artigo é defender a ideia de que somente decompondo o espaço e levando em consideração suas dimensóes física, estrutural e sócio-histórica - é possível compreender os limites da Justiça do Trabalho na plantation açucareira no nordeste do Brasil. Proponho que a análise espacial e geográfica das relações sociais é condição sine qua non para um entendimento mais sólido dos embates de classe e das condiçóes de vida dos trabalhadores nessa região. Argumento que o cruzamento dos dados disponíveis nos processos trabalhistas com uma refinada análise cartográfica que possibilite identificar a localização dos engenhos, em função das sedes de municípios e da rede viária, torna possível pensar a sociedade a partir de uma perspectiva desafiadora. Uma abordagem espacial da história oferece a oportunidade de analisar fontes tradicionais de pontos de vista inovadores. A partir dela, é possível desenhar um quadro detalhado dos conflitos e das condiçóes de vida dos trabalhadores, uma vez que o espaço exerce um papel de extrema relevância na análise social. Como afirma, na sua Física, a máxima aristotélica: o que não está em nenbum lugar não existe... A sociedade açucareira é inconcebível fora de sua condição espacial. Os conflitos trabalhistas na plantation são inconcebíveis fora do espaço.

A plantation açucareira (da qual faziam parte municípios inteiros, incluindo suas cidades e tribunais do trabalho) era um espaço em que a mobilidade livre dos trabalhadores existia somente como possibilidade, como potência. Nela, os engenhos, unidades básicas que lhe garantiam existência e preservação, eram, ao mesmo tempo, local de moradia e trabalho para centenas de milhares de pessoas. Eram territórios ${ }^{2}$ de domínio da classe patronal, onde ela podia, livre e impunemente, exercer total controle por meio da violência e coerção (ANDRADE, 1963; GARCIA, 1989; DABAT, 2012; ROGERS, 2017). Espaço, para os propósitos deste artigo, deve ser entendido como um “[...] conjunto indissociável, solidário e também contraditório de sistemas de objetos [no nosso caso em foco: cidades, plantações, estradas, rodovias, usinas, engenhos, matas, rios, animais, trabalhadores...] e sistemas de ações [relaçôes sociais], não considerados isoladamente, mas como um quadro único no qual a história se dá” (SANTOS, 2006, p. 39). Resulta disso que pensar a história do açúcar a partir de um enfoque espaço-temporal é encará-la não simplesmente como uma somatória de elementos geográficos e sociais, mas como fruto de um único e complexo sistema de interaçóes geográficas e sociais; como um aparelho de encadeamentos recíprocos, em que objetos e ações se influenciavam mutuamente.

A história da justiça do trabalho na zona canavieira de Pernambuco (Figura 1) está diretamente ligada às grandes mobilizações sociais, em todo o Brasil, nos anos que antecederam o Golpe de 1964. 
Nessa época, o estado foi palco do surgimento das Ligas Camponesas e de diversas greves promovidas pelos assalariados rurais organizados do setor sucroenergético. Dois anos antes dos militares tomarem o poder, o presidente João Goulart, por meio da Lei 4.088/62, criou JCJs nos municípios de Jaboatão, Goiana, Nazaré da Mata, Escada, Palmares e Caruaru, todas, com exceção da última, localizadas na chamada Zona da Mata pernambucana, área dominada por latifúndios de cana há cinco séculos. Em 1963, foi promulgado o Estatuto do Trabalhador Rural (ETR), Lei 4.214/63, pondo fim ao vazio jurídico ${ }^{3}$ no campo (PRADO JÚNIOR, 1979). Nesse mesmo ano, sob o primeiro e inacabado governo de Miguel Arraes, foi assinado o Acordo do Campo e instituída a chamada Tabela de Tarefas que, diferentemente do Estatuto (mais genérico e, portanto, passível de ser descumprido com maior facilidade), discriminava o salário equivalente a cada tipo de serviço na cultura da cana. ${ }^{4}$

Figura 1 - Municípios da zona canavieira de Pernambuco (anos 1960)



Fonte: ANDRADE, Manuel Correia de; ANDRADE, Sandra Maria Correia de. A cana-de-açúcar na região da mata de Pernambuco. Reestruturação Produtiva na Área Canavieira de Pernambuco nas décadas de 80 e 90: Impacto Ambiental. Sócio-Econômico e Político. Recife: Editora Universitária da UFPE, 2001.

É nesse rico e complexo contexto de mobilizaçôes, conquistas e retrocessos que se situa a história da instalação das JCJ na zona canavieira e das tentativas de acessá-las a partir de um mundo isolado, distante e controlado por milícias privadas fortemente armadas (CONTAG, 1984; SIGAUD, 1986; GARCIA, 1989). Contudo, se, em termos jurídicos, as Juntas de Conciliação significaram quase uma revolução nos padróes de resolução de conflitos trabalhistas no mundo do açúcar - porque até então os senhores de engenho eram homens todo poderosos, polícia e justiça dentro de suas terras, como destacou Júlio Bello (1995, p. 179) em suas Memórias de um senhor de engenho - seu efeito 
real e concreto no cotidiano dos assalariados não foi tão amplo. Para deslocar-se até uma Junta e "botar uma questão", por exemplo, os moradores de engenho precisavam vencer uma série de barreiras como: a) distância quilométrica dos engenhos em relação aos tribunais; b) precariedade das vias que lhes davam acesso; c) falta de transporte público regular que permitisse sair dos engenhos; e d) medo de tornarem-se vítimas de violência por parte de patróes vingativos (ABREU e LIMA, 2005). Para investigar a dimensão espacial dos conflitos trabalhistas no Nordeste açucareiro e repensar os limites da Justiça do Trabalho na plantation, é necessário, pois, proceder a uma análise ao mesmo tempo crítica e dialética que considere a complexidade dessas dimensões.

Tomando por base sua dimensão puramente física, a plantation era formada essencialmente por duas partes: o mundo externo e o mundo dos engenhos. Na primeira, era possível localizar as sedes municipais e a maior parte dos serviços essenciais, como hospitais, postos médicos, escolas, delegacias, juntas trabalhistas, bancos, mercados públicos etc. Também era no mundo externo onde o sistema de transporte público atendia o maior número de pessoas, porque, dentre outros motivos, ele contava com uma rede mais ampla de rodovias pavimentadas. Diferentemente do mundo externo, o mundo dos engenhos era composto basicamente por unidades produtivas distantes das cidades, isoladas, desprovidas, em sua maior parte, de condiçóes básicas de saúde, saneamento, segurança, escolarização etc. Acessível, em grande parte, apenas por vias não pavimentadas, inseguras, de difícil locomoção, que constituíam verdadeiros labirintos para aqueles que viviam fora de suas fronteiras, o mundo dos engenhos concentrava, desde o período colonial até pelo menos o final do século XX, centenas de milhares de trabalhadores. Para que se tenha uma ideia, de acordo com o Levantamento socioeconômico das pequenas localidades na Zona da Mata Sul - relatório técnico, divulgado em 1987, realizado por uma equipe composta por vinte e quatro membros do Governo do Estado de Pernambuco - cerca de trezentas mil pessoas ainda moravam nos engenhos e agrovilas apenas na porção meridional da zona canavieira nessa época. O documento registra ainda que esses engenhos eram "[...] povoados ilhados pela cultura da cana-de-açúcar [...], 'depósito' de mão de obra da reserva cativa [...]” e que uma "estrutura conservadora e hermética” era responsável pelo "[...] total isolamento em que viv[ia]m [i. e. os moradores de engenho], privados, como se encontra[va]m, do acesso a equipamentos que lhes possibilit[asse]m condiçóes dignas de saúde, moradia e educação” (CONDEPE/FIDEM, 1987, p. 8).

As Figuras de dois a cinco - elaboradas a partir das cartas da Superintendência do Desenvolvimento do Nordeste (Sudene) - permitem visualizar melhor as distâncias métricas e o grau de isolamento, em relação às cidades e aos poderes públicos externos, dessas unidades produtivas seculares. Uma leitura detalhada da localização exata de cada engenho, bem como da extensão e qualidade do sistema viário, autoriza, em primeiro lugar, concluir que, em toda a zona canavieira, a maior parte deles só era acessível por vias não pavimentadas. Essa constatação é particularmente visível para a Mata Sul, onde a maior parte das terras dominadas pela cana só podia ser acessada por caminhos de barro com tráfego periódico. Como é visível nas Figuras dois e três, o extenso quadrilátero formado pelas cidades de Escada, Cabo, Vitória de Santo Antão e Jaboatão, por exemplo, abrigava vários engenhos que para serem visitados era imperativo tomar caminhos precários que se bifurcavam por dentro do imenso "mar de cana”. Na maior parte da Mata Norte, ao contrário, sobretudo na área que se estende entre Carpina e a fronteira com o estado da Paraíba, as estradas, embora igualmente 
não pavimentadas, eram transitáveis em todas as estações. A presença de diversos sítios e fazendas (Figuras quatro e cinco) não impedia a predominância da cana-de-açúcar também nessa região, onde os engenhos localizavam-se, igualmente, em pontos distantes das cidades.

Figura 2 - Localização dos engenhos e sistema rodoviário na Zona da Mata Sul, Pernambuco, 1972

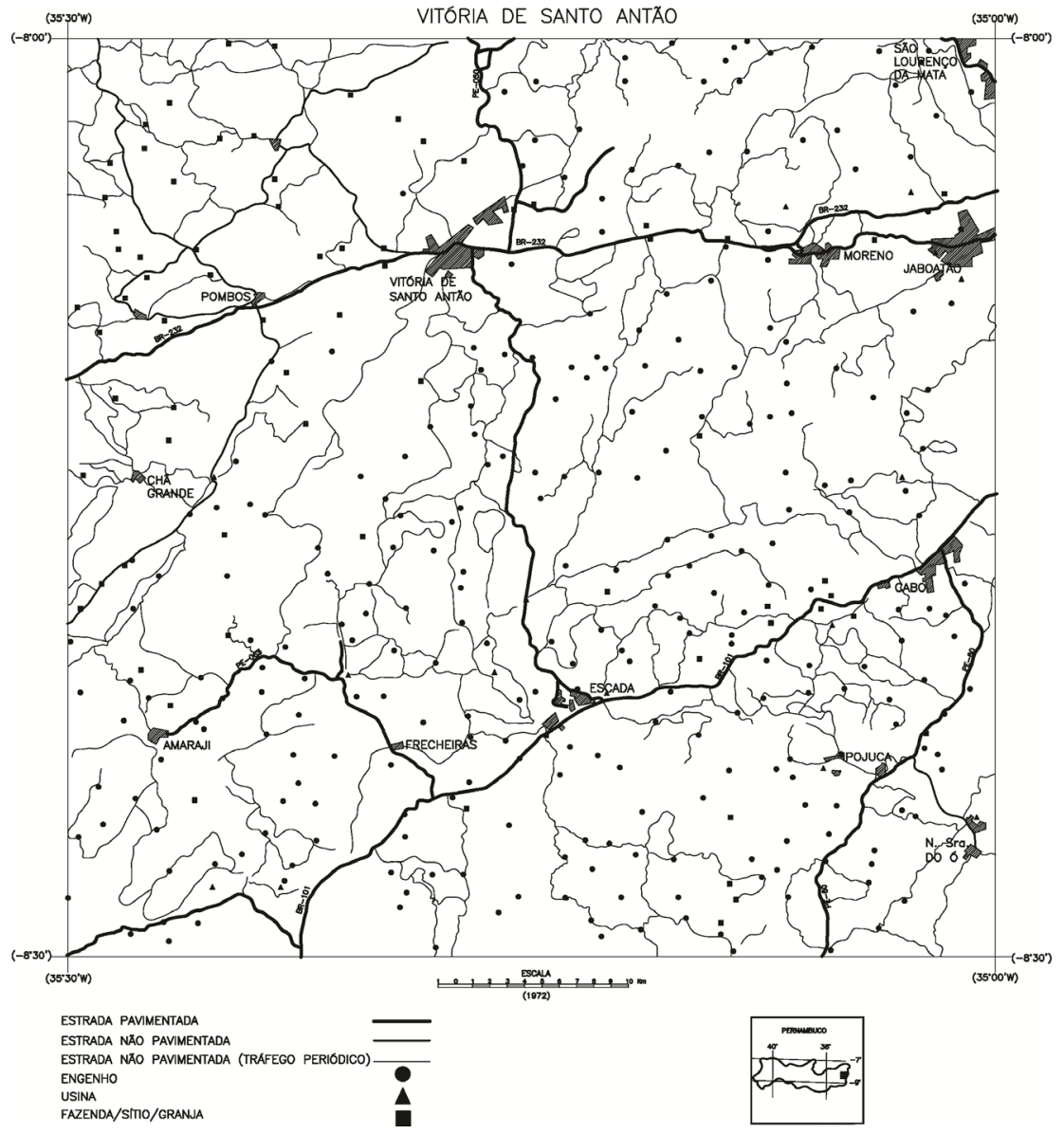

Fonte: Elaborada pelo autor a partir das cartas da Sudene.

Figura 3 - Localização dos engenhos em relação às estradas pavimentadas (imagem 1), estradas não pavimentadas com tráfego permanente (imagem 2) e estradas não pavimentadas com tráfego periódico (imagem 3) na Zona da Mata Sul, Pernambuco, 1972
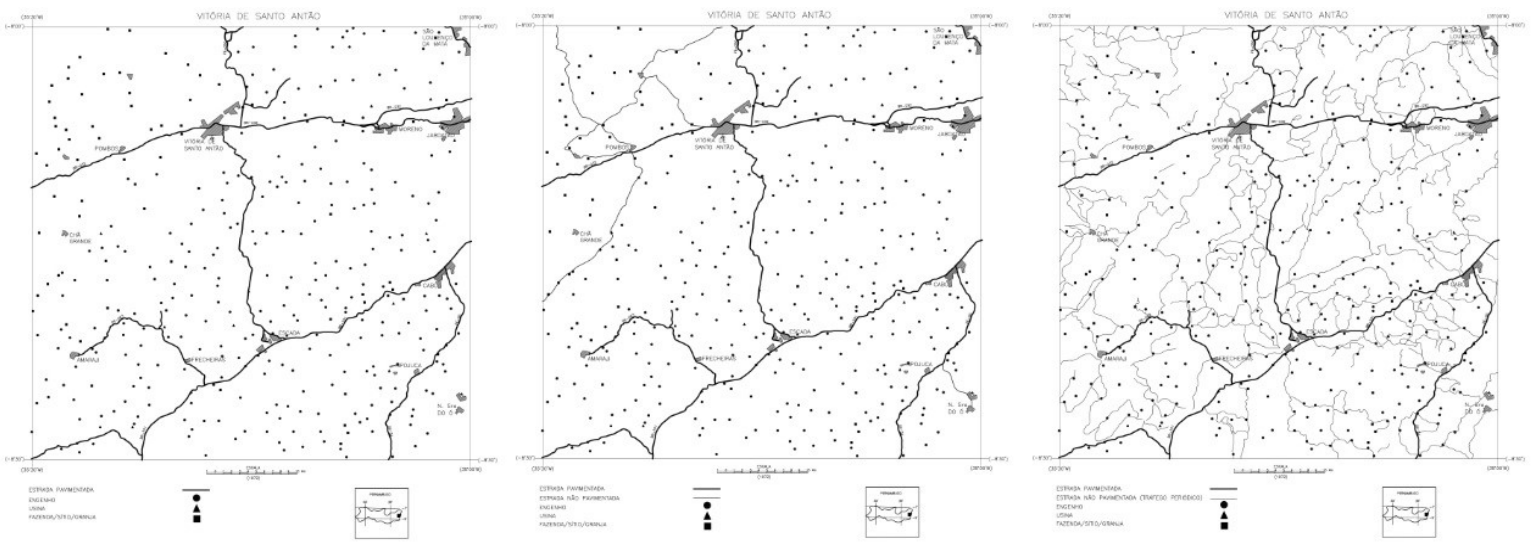

Fonte: Elaborada pelo autor a partir das cartas da Sudene. 
Figura 4 - Localização dos engenhos e sistema rodoviário na Zona da Mata Norte, Pernambuco, 1972

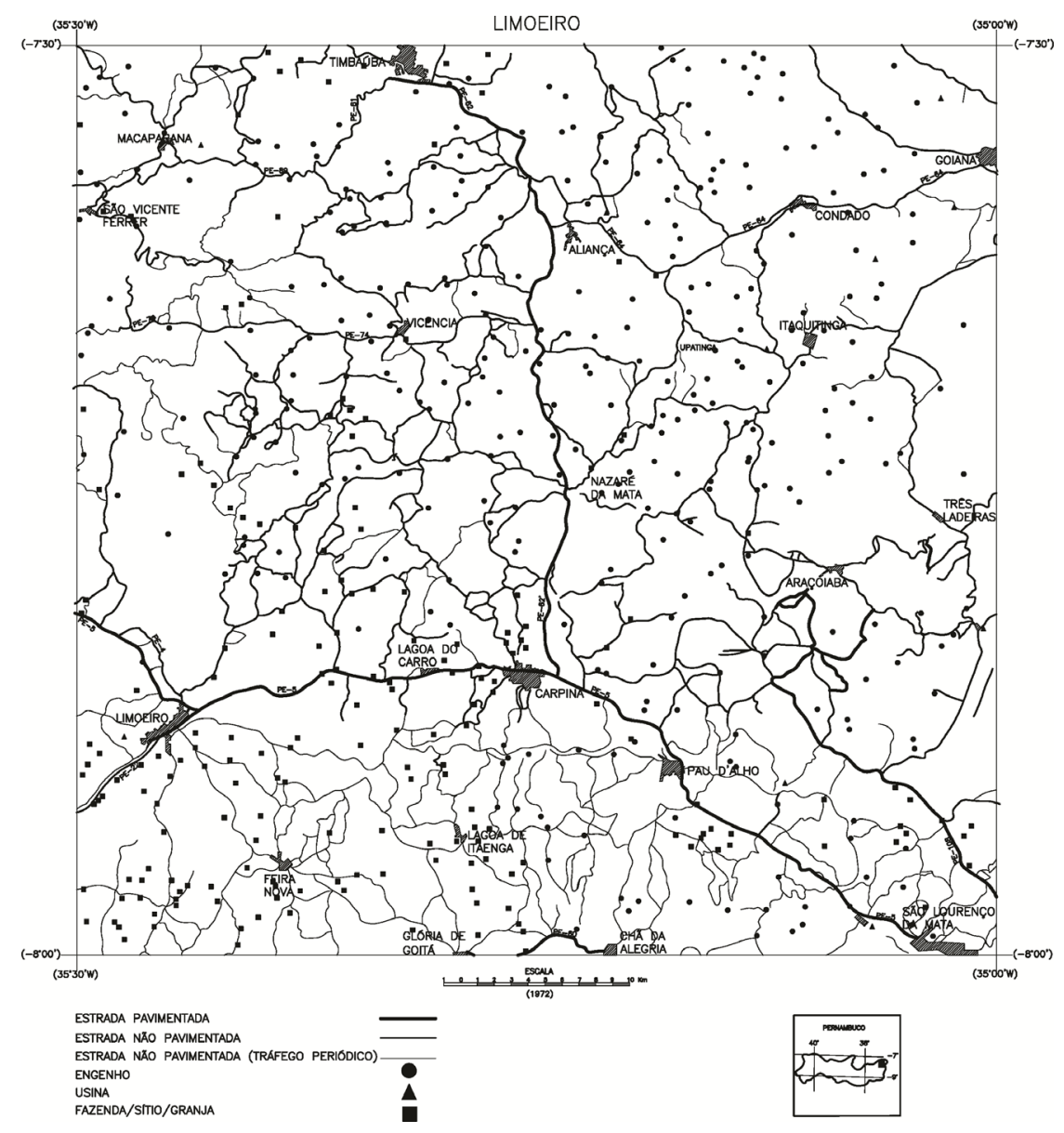

Fonte: Elaborada pelo autor a partir das cartas da Sudene.

Figura 5 - Localização dos engenhos e usinas em função das estradas pavimentadas (imagem 1), estradas não pavimentadas com tráfego permanente (imagem 2) e estradas não pavimentadas com tráfego periódico (imagem 3) na Zona da Mata Norte, Pernambuco, 1972



Fonte: Elaborada pelo autor a partir das cartas da Sudene. 
A partir da análise de todas as cartas da Sudene que abrangem a Zona da Mata (65 ao todo, o que corresponde a aproximadamente $85 \%$ da área de cana plantada no estado), constatei que a média das distâncias métricas lineares ("voo de pássaro") entre os 992 engenhos identificados e as sedes de municípios mais próximas era de sete quilômetros. As informações sobre 159 engenhos apresentadas no Levantamento socioeconômico das pequenas localidades, anteriormente mencionado, por outro lado, permitiram-me constatar que a média das distâncias métricas reais entre eles e as sedes de municípios mais próximas, na Mata Sul, era de treze quilômetros. Na zona canavieira, essas questóes eram particularmente importantes, porque a maior parte dos moradores de engenho deslocava-se a pé ou no lombo de animais, dada a ausência de um sistema de transporte público ofertado pelo Estado ou mesmo particular disponibilizado pelos senhores. Obviamente, o cálculo das distâncias métricas não leva em consideração a dimensão psicológica que permeava aqueles que se deslocam e as sinuosidades e condiçóes das vias pelas quais se deslocam, nem os fatores ecológicos e as asperidades do relevo que ampliam as distâncias reais. Uma vez que as distâncias podem ser apreendidas tanto em termos físicos quanto temporais, psicológicos e econômicos (RAFFESTIN, 1993), na plantation, elas não respondiam apenas a um referencial métrico absoluto, mas estavam vinculadas também a padrões culturais e históricos. Nela os indivíduos não dispunham da mesma mobilidade nem eram capazes de utilizar todas as estradas e todos os veículos sob condições idênticas. ${ }^{5}$ Eles não eram igualmente móveis, nem igualmente imóveis. No mundo do açúcar, tanto para os trabalhadores como para o capital, a ideia de distância não tem significação se não se faz referência à estrutura de classes, ao "valor" histórico dos lugares e à possibilidade de manipulação dos territórios.

O isolamento de algumas usinas não era diferente dos engenhos, embora o setor sucroalcooleiro tenha exercido notória influência na direção do traçado de diversas rodovias implementadas na Zona da Mata ao longo da segunda metade do século XX. A antropóloga Marie France Garcia (1977, p. 1), que realizou pesquisa de mestrado na zona canavieira, detalhou as dificuldades para acessar a Usina de Goiabeiras (codinome de seu campo de estudo):

A usina de Goiabeiras está localizada no meio de uma vasta área de cana-de-açúcar e é isolada pelo fato de não ser servida por transporte público regular. Para ter acesso a ela, o mais fácil é partir de Imperatriz, cidade mais próxima ligada a Goiabeiras por $25 \mathrm{~km}$ de estrada de terra carroçável quase o tempo todo. As outras vias de acesso são não apenas mais longas, mas impraticáveis de carro em tempos de chuva, ou seja, durante o inverno [...]. Durante a viagem atravessam-se vários engenhos, mas para o viajante que vem de fora não existe divisão aparente.

$\mathrm{Na}$ região açucareira da Bahia, em meados do século XX, os relatos de Harry William Hutchinson, em Village and plantation life in Northeastern Brazil (1957, p. 19), apontam igualmente que, no Recôncavo, “[...] não [havia] transporte público no interior [...]” dos engenhos e o trem, que não era utilizado pelos moradores da cidade, normalmente ficava muito longe. A maioria da população precisava andar para todos os lugares em que ia. Para o autor, "[...] o sentimento de isolamento e abandono [era] forte” (1957, p. 65). A falta de transporte público no mundo dos engenhos era um padrão na plantation. Isso permitia às empresas exercer forte domínio sobre a força de trabalho confinada. Como a antropóloga Beatriz Alásia de Heredia afirmou, em Formas de dominação e espaço social (1988, p. 116), referindo-se a Alagoas, “[...] para garantir a mão de obra necessária era preciso [...] imobilizá-la, e o engenho o fez, fixando-a dentro dos limites da propriedade”. O geógrafo Mário Lacerda de Melo, em Paisagens do Nordeste em Pernambuco e Paraíba (1959, 
p. 111), também admitiu que "[...] os engenhos [...] forma[va]m, todos eles, um sistema coeso, dominado pela força industrial centralizadora”.

Como está claro, somadas as distâncias, a falta de transporte público e a precariedade das vias representavam igualmente barreiras a serem vencidas na tentativa de sair do hermético mundo dos engenhos. Ainda segundo o Levantamento socioeconômico, uma das mais importantes fontes de informações sobre as condições de vida em seu interior, o acesso viário aos engenhos da Mata Sul "[...] [era] precário, com estradas carroçáveis, intransitáveis nos períodos chuvosos, isolando os povoados por períodos que duravam até seis meses”. Em épocas de chuvas, até os automóveis ficavam impossibilitados de transitar, pois era comum trechos alagados com extensão superior a cem metros (CONDEPE/FIDEM, 1987, p. 10). O sistema ferroviário, por seu turno, durante certo tempo bastante capilar na Mata Sul, serviu, quase que exclusivamente, para transportar a cana colhida, do canavial até a fábrica. Seu traçado era basicamente determinado pelo setor empresarial. Segundo Manuel Correia de Andrade (1987, p. 142), “[...] chegou-se ao extremo de os trilhos das usinas somarem mais, no total, que os de serviço público”. Fora de Pernambuco, esse padrão era reproduzido quase como um imperativo da plantation. Na Paraíba, por exemplo, de acordo com Orlando Valverde, em artigo na Revista Brasileira de Geografia (1955, p. 53), “[...] a utilização do solo [era] cuidadosamente planejada; tudo em função do rei açúcar [...] As estradas de ferro e de rodagem esgueira[va]m-se pela base dos tabuleiros, à margem dos canaviais. A ferrovia [tinha] estações cujo único fim [era] servir às usinas”.

Se o deslocamento dos engenhos para as cidades respondia a todos esses inconvenientes, ir até uma corte para abrir um processo trabalhista era ainda mais complicado. Para isso, o reclamante precisaria, em muitos casos, atravessar várias cidades, uma vez que a Lei 4.088/62 instalou apenas cinco Juntas com jurisdição estendida sobre trinta municípios da Zona da Mata. A Junta de Escada, por exemplo, tinha jurisdição sobre uma área que corresponde hoje em dia a $2.997,062 \mathrm{~km}^{2}$, já que ela também poderia receber demandas dos trabalhadores provenientes dos municípios de Ribeirão, Cortês, Rio Formoso, Barreiros, Amaraji, Cabo, Ipojuca e Sirinhaém. Ademais, o dia de trabalho que o morador de engenho perderia ao fazer isso era descontado de seu salário. Os custos de alimentação e transporte também ficavam por sua conta. Além disso, a prática corrente dos engenhos pagarem os moradores com vales ${ }^{6}$ funcionava como mais um limitante, porque o valor monetário dessa moeda se restringia aos limites da propriedade, não sendo aceita, portanto, no mundo externo.

O medo, finalmente, era outro elemento da plantation que impunha limites à Justiça do Trabalho e ampliava as distâncias entre os engenhos e o mundo externo, uma vez que, como os elementos físicos do espaço, ele influía na capacidade de se deslocar para dentro e/ou para fora das plantations. Como pontuou Manuel Correia de Andrade, em Lutas camponesas no Nordeste (1989, p. 22), “[...] se reagiam [os trabalhadores] recorrendo à justiça, eram muitas vezes ameaçados de morte ou de destruição de seus bens”. Sobre essa questão, ele ainda acrescenta:

Numerosos proprietários, sabendo que os trabalhadores não tinham condições de questionar [na justiça], passaram a tomar represálias, perseguindo, prendendo e batendo naqueles que no período anterior [ao Golpe de 1964] se destacaram como reivindicadores [em açôes 
trabalhistas]. Dominou um período de terror no campo, mas o Estatuto do Trabalhador Rural não foi revogado e continuou, embora em condições precárias, a ser aplicado em algumas áreas [...] (ANDRADE, 1989, p. 46).

Em todo esse quadro - que englobava distância dos engenhos em relação aos centros urbanos, isolamento, acesso precário, ausência de transporte, medo - os poderes públicos, o Estado, propriamente, encontrava-se ausente e omisso, a não ser na "tradicional dimensão repressiva" (DABAT, 2012, p. 104), já que, segundo Lygia Sigaud (1986, p. 319), as “[...] forças repressivas do governo do estado [...], à exceção do curto período do governo Miguel Arraes, sempre foram utilizadas contra os trabalhadores e a favor dos proprietários".

De fato, a lógica desse sistema de exploração parecia ser bastante simples: o isolamento dos engenhos permitia e facilitava o uso da violência em seu interior; e esta, por sua vez, alargava, na dimensão cognitiva real, as fronteiras com o mundo externo e era utilizada para coagir a classe trabalhadora e impor-lhe certo nível de medo que a levava a uma quase imobilização. Violência e medo não apenas compunham a própria plantation - como aqueles elementos sem os quais ela não poderia ser - mas também eram indispensáveis à sua manutenção. Combinada à forma labiríntica, isolada e concentracionária dos engenhos, ela funcionava também como componente-chave do espaço, modelando a paisagem açucareira.

Uma análise da dimensão geográfica e espacial da plantation, portanto, é indispensável para uma compreensão mais acurada dos limites da Justiça do Trabalho no mundo do açúcar. A esse respeito, os milhares de processos disponíveis nos arquivos do TRT 6a Região permitem-nos construir uma história espacial dos conflitos trabalhistas no Nordeste açucareiro. A identificação da localização dos engenhos de onde partiram os reclamantes em relação ao sistema viário, por exemplo, revela que o percentual daqueles que viviam nas áreas mais distantes e isoladas (com acesso apenas por estradas com tráfego periódico) era notoriamente menor do que aqueles que viviam em regióes de acesso menos precário, como mostram as Figuras seis e sete. Se associarmos esse dado primeiro ao fato de apenas uma pequena parcela da população, em relação ao total, ter aberto processo e, segundo, ao fato, igualmente importante e amplamente registrado na historiografia, de que a precariedade das condições de vida, o descumprimento da legislação trabalhista e a violência patronal representavam invariáveis no Nordeste açucareiro, podemos concluir que a configuração espacial concentracionária da plantation impediu a maior parte dos trabalhadores reclamarem. Embora não possamos calcular o número de trabalhadores que deixaram de acessar a Justiça, é possível inferir que a maior parte deles não o fez porque as forças de concentração (que dificultavam a saída das unidades produtivas) eram maiores que as de forças de dispersão (que facilitavam o deslocamento para fora do mundo dos engenhos). 
Figura 6 - Localização da residência dos reclamantes na JCJ Escada (1964-1968) e sistema rodoviário na Zona da Mata Sul, Pernambuco



Fonte: Elaborada pelo autor a partir do cruzamento entre os dados do TRT 6 e as cartas da Sudene.

Figura 7 - Localização da residência dos reclamantes na JCJ Nazaré da Mata (1963) e sistema rodoviário na Zona da Mata Norte, Pernambuco



Fonte: Elaborada pelo autor a partir do cruzamento entre os dados do TRT 6 e as cartas da Sudene. 
É amparado nesses dados e nessa lógica que defendo a ideia de que não é possível compreender os impactos das leis e da Justiça no cotidiano dos moradores de engenho sem levar em consideração a espacialização dos conflitos trabalhistas. Minha tese é que, na prática, as Juntas não garantiam o cumprimento dos códigos legais e o fim das (in)justiças no mundo do açúcar e isso se dava, sobretudo, em decorrência da arquitetura espacial da plantation, alicerçada no domínio territorial exercido pela classe patronal organizada. Se, como demonstrou Moema Miranda (1991), antes da instalação das JCJs tanto o processo de trabalho quanto a solução das divergências dele decorrentes eram definidos dentro dos muros da propriedade - a partir de critérios tradicionais e tendo como referência a autoridade legítima do senhor para desempenhar o papel de árbitro - depois delas esse padrão persistiu, dadas as barreiras físicas, estruturais e sócio-históricas enfrentadas pela classe trabalhadora na tentativa de acessá-las se deslocando para fora do mundo isolado dos engenhos. Se é verdade que o Estatuto e as Juntas abriram brechas e precedentes legais bem aproveitados por parte da classe trabalhadora em ações deprecadas em todo o país ao longo da Ditadura Militar; se é verdade que elas deram vazão institucional a uma série de lutas acumuladas desde a abolição; se é verdade que elas serviram como fonte de insolência, posto que os conflitos antes resolvidos em termos pessoais passaram a ser mediados institucional e publicamente; se é verdade que elas pesavam sobre os ombros dos patróes ante a possibilidade de terem que responder judicialmente as acusações de irregularidades praticadas em seus domínios... é igualmente verdade que, ao menos na zona canavieira Pernambucana, leis e tribunais ameaçavam o poder arbitrário e privado dos senhores apenas no campo jurídico e simbólico, posto que, num ambiente geograficamente distante e isolado, dominado por milícias que controlavam cada centímetro do território, a Justiça era dificilmente acessível aos moradores e servia basicamente para homologar práticas sistemáticas de ilegalidades trabalhistas. Em que pese o papel desempenhado pelo ETR e pelas Juntas, parte da literatura superestimou seu alcance por ter suposto que apenas o número elevado de processos trabalhistas prefigurasse avanços e rupturas dignas de nota numa sociedade sustentada por exploração e violência seculares. ${ }^{7}$ Isso não significa dizer, contudo, que seus efeitos foram nulos e irrelevantes, senão que elas foram criadas basicamente como mecanismo de apaziguamento e contenção social (de conciliação) num contexto de grandes mobilizações de trabalhadores em defesa de uma revolução no campo, via reforma agrária, nos anos 1960.

Apesar do caráter concentracionário do mundo do açúcar; da precariedade das vias que lhes davam acesso; da falta de transporte público e das violências e ameaças promovidas pela classe patronal, como destaquei até aqui, centenas de trabalhadores (sobretudo moradores de engenhos próximos às Juntas, mas também daqueles mais isolados), mesmo depois do Golpe de 1964, organizaram-se (inclusive coletivamente) e conseguiram deixar o mundo fechado das plantations para reclamar na Justiça. As figuras oito a onze, por exemplo, mostram as localizaçóes, as nuances e declividades do relevo (representadas nas curvas de nível), da vegetação e das estradas, além da dispersão das casas dos moradores (representada pelos pontos pretos da carta) no imenso mar de cana onde estavam instalados o Engenho São Manoel e a Usina Liberdade, na margem direita e esquerda do Rio Pirapama. Corroborando os dados das cartas de 1971, Gilberto Osório de Andrade e Raquel Caldas Lins Andrade (1984, p. 141) constataram que, na Bacia do Pirapama, “[...] à exceção de algumas rodovias de terra batida melhor conservadas nas vizinhanças de usinas de 
açúcar e de destilarias [...]”, a "[...] densa urdidura de caminhos vicinais [era], às vezes, [impraticável] na estação das chuvas”. De lá, contudo, partiram Josefa Bezerra de Lima ${ }^{8}$ e José Onofre da Silva. $\mathrm{Na}$ Junta de Escada, os dois trabalhadores reclamaram férias (Josefa também, o décimo terceiro salário e a diferença salarial) e anotação da Carteira Profissional. Ambos os processos foram arquivados, porque os reclamantes deixaram de comparecer ao tribunal no dia da audiência. Se o fato de moradores de engenhos tão isolados acessarem a Justiça poderia pôr em xeque minha tese central (aquela que defende que os arranjos territoriais na plantation dificultavam ou mesmo impediam a maioria dos trabalhadores de saírem do mundo dos engenhos), os arquivamentos reforçam meu argumento que insiste em destacar, ao mesmo tempo, a capacidade de resistência dos trabalhadores e os limites espaciais (com suas múltiplas variáveis) da Justiça do Trabalho. Se apenas conjecturas podem ser feitas sobre os reais motivos que levaram Josefa e José a faltarem à audiência, não se pode duvidar, contudo, de que as distâncias e o isolamento de onde viviam, a falta de transporte público, a precariedade das estradas e as práticas sistemáticas de violências não tenham exercido influência alguma sobre o desfecho de seus pleitos na Justiça. Portanto, tão importante quanto compreender o perfil dos trabalhadores que acessaram as Juntas de Conciliação e Julgamento - sua idade, sexo, estado civil, nível de alfabetização, direitos reclamados etc. - e as formas de resolução dos conflitos no judiciário (conciliações, arquivamentos, julgamentos, desistências) é problematizar os padróes das dinâmicas territoriais (e seus desdobramentos no cotidiano) próprios da plantation açucareira no nordeste do Brasil.

Figura 8 - Localização do Engenho São Manoel e da Usina Liberdade em relação à Junta de Conciliação e Julgamento de Escada, Zona da Mata, Pernambuco

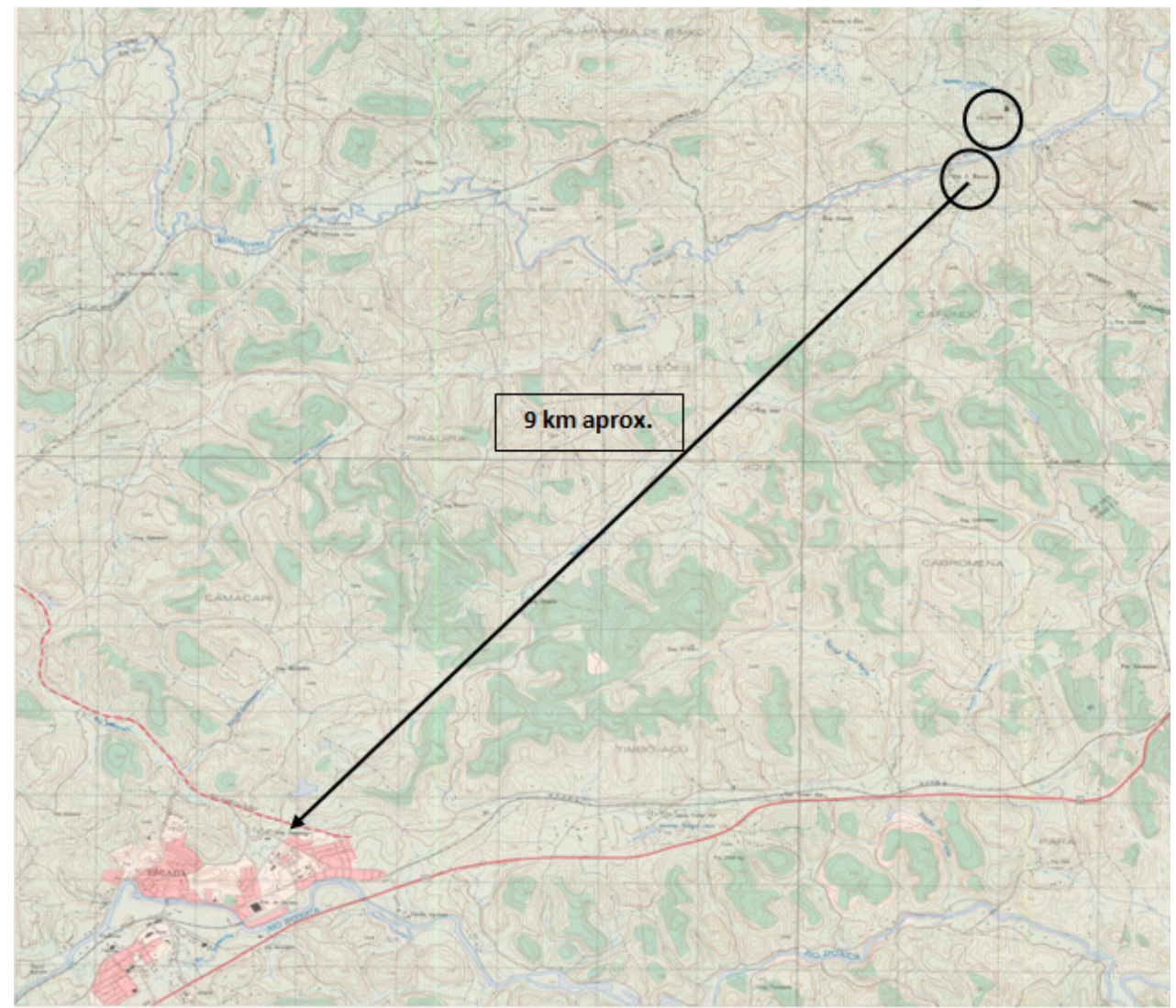

Fonte: Carta da Sudene (fotografias aéreas, escala 1: 30 000, de 1970/1971). 
Figura 9 - Detalhe da localização do Engenho São Manoel e da Usina (engenho) Liberdade

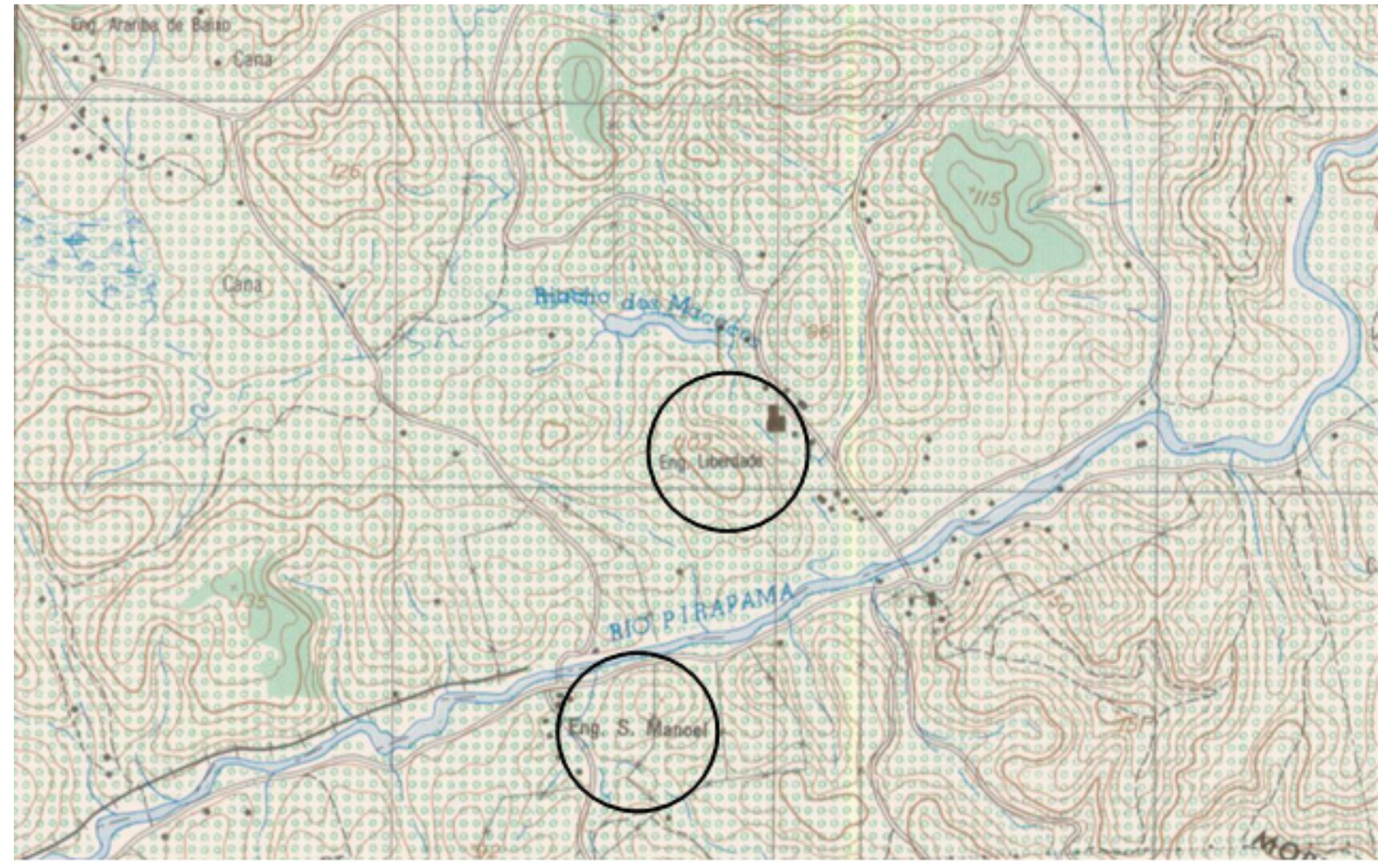

Fonte: Carta da Sudene (fotografias aéreas, escala 1: 30 000, de 1970/1971).

Figura 10 - Fotografia aérea do Engenho São Manoel e da Usina Liberdade

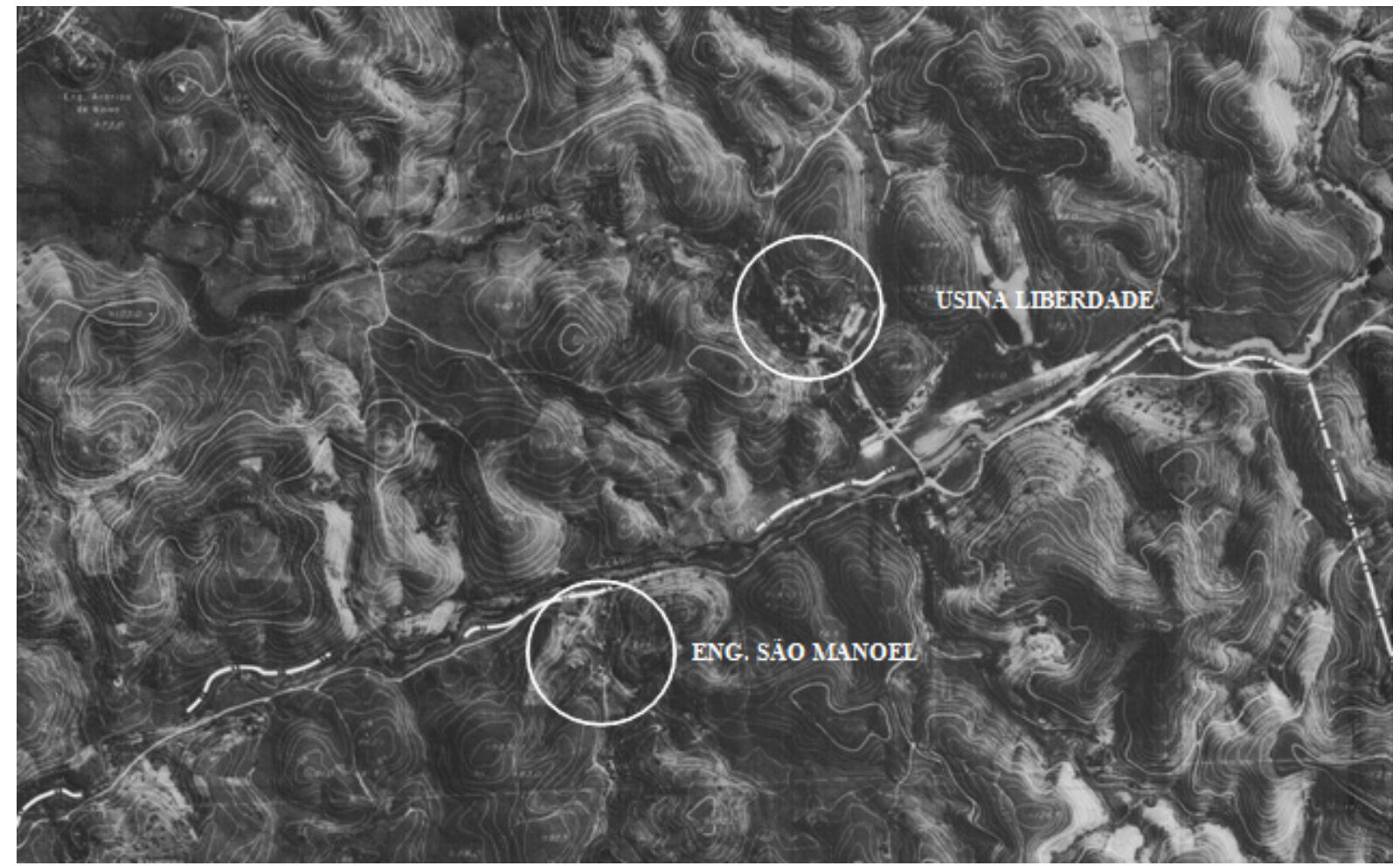

Fonte: Ortofotocarta n. 6800, escala 1:10 000, de 19/05/1975, disponível no Condepe/Fidem. 
Figura 11 - Detalhe aéreo do parque industrial da Usina Liberdade

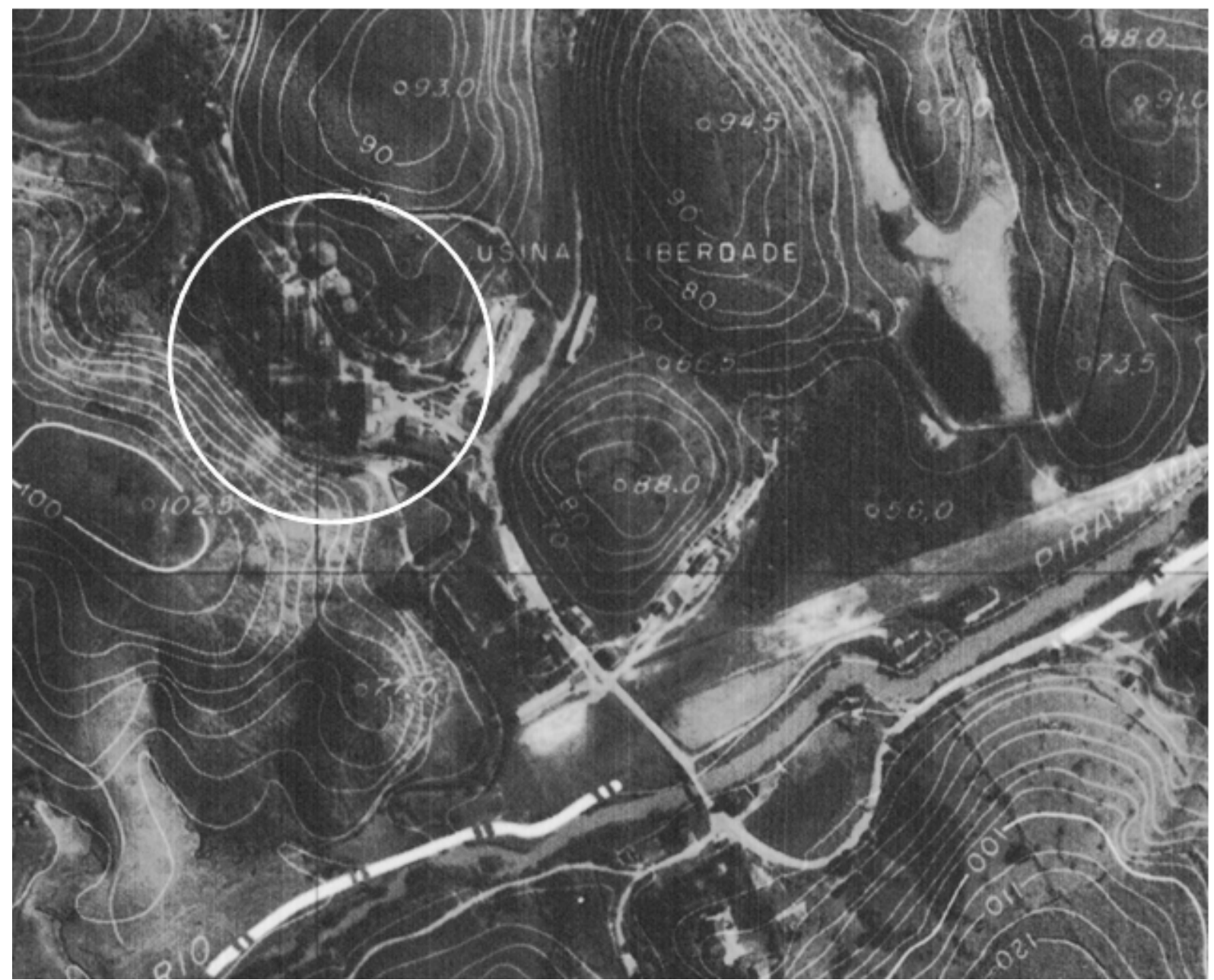

Fonte: Ortofotocarta n. 6800, escala 1:10 000, de 19/05/1975, disponível no Condepe/Fidem.

Este artigo foi uma tentativa objetiva, mais ou menos explícita ao longo de suas páginas, de propor uma nova forma de pensar e abordar (a partir de uma análise espacial e geográfica) as condições de dominação da classe patronal sobre os moradores de engenho e os limites espaciais da Justiça do Trabalho na zona canavieira. O mais importante, contudo, é que essa dominação se realizava menos por um simples limite métrico e pela distância e dispersão das unidades produtivas, com relação aos centros de poder público, do que pelo estabelecimento de um complexo e sofisticado sistema de controle que ela permitia, pois os problemas de mobilidade, ou o princípio lógico da antimobilidade (ideal patronal), entre o mundo dos engenhos e o mundo exterior - que tornavam a Justiça quase inacessível, como tentei demonstrar - faziam parte da própria arquitetura espacial da plantation. 


\section{Referências}

ABREU E LIMA, Maria do Socorro. Construindo o sindicalismo rural: lutas, partidos, projetos. Recife: EdUFPE \& Editora Oito de Março, 2005.

ANDRADE, Gilberto Osório de; ANDRADE, Raquel Caldas Lins. Pirapama: um estudo geográfico e histórico. Recife: Editora Massangana, 1984

ANDRADE, Manuel Correia de. A terra e o homem no Nordeste. Rio de Janeiro: Brasiliense, 1963.

ANDRADE, Manuel Correia de. Abolição e reforma agrária. São Paulo: Ática, 1987.

ANDRADE, Manuel Correia de. Lutas camponesas no Nordeste. 2. ed. São Paulo: Ática, 1989.

ARISTÓTELES. Física I e II. Campinas: Editora da Unicamp, 2009.

BARBALHO, Nelson. Dicionário do açúcar. Recife: Massangana, 1984.

BELLO, Júlio. Memórias de um senhor de engenho. Recife: Fundarpe, 1985.

CONDEPE/FIDEM - Agência Estadual de Planejamento e Pesquisa de Pernambuco. Levantamento socioeconômico das pequenas localidades na Zona da Mata Sul. Secretaria de Planejamento, Fundação de Desenvolvimento Municipal do Interior de Pernambuco (Fiam). vol. I e II, 1987.

CONTAG. A violência no campo pela mão armada do latifúndio (1981-jun. 1984): torturas, prisões, espancamentos, assassinatos, impunidade e expulsão dos trabalhadores da terra. In: A estrutura agrária e a violência no campo, em Brasília, Distrito Federal.

DABAT, Christine Rufino; ROGERS, Thomas D. 'A peculiarity of labor in this region': workers' voices in the labor court archive at the Federal University of Pernambuco". In: LARR, v. 47, n. 4, 2012

DABAT, Christine Rufino; ROGERS, Thomas D. Sugarcane Workers in Search of Justice: Rural Labour through the Lens of the State. In: International Review of Social History, v. 62, 2017.

DABAT, Christine Rufino. Moradores de engenho: estudo sobre as relações de trabalho e condições de vida dos trabalhadores rurais na zona canavieira de Pernambuco, segundo a literatura, a academia e os próprios atores sociais. 2. ed. Recife: EdUFPE, 2012.

DABAT, Christine Rufino. Uma 'caminhada penosa': a extensão do direito trabalhista à zona canavieira de Pernambuco. In: Clio: Revista de Pesquisa Histórica. Recife: EDUFPE, v. 26, n. 2, 2008.

FERREIRA FILHO, José Marcelo Marques. Arquitetura espacial da plantation açucareira no nordeste do Brasil (Pernambuco, século XX). Recife: EdUFPE, 2020. [No prelo].

GALVÃO, Michel Cavassano. Processos de trabalhadores da agroindústria açucareira na Junta de Conciliação e Julgamento de Jaboatão de 1963 a 1965. In: Cadernos de História: oficina da História. Trabalhadores em Sociedades Açucareiras. Recife: EdUFPE, 2010.

GARCIA, Afrânio Raul. Libres et assujettis: marché du travail et modes de domination au Nordeste. Paris: Éditions de la Maison des Sciences de l'Homme, 1989.

GARCIA, Afrânio Raul. O Sul: caminho do roçado. Estratégias de reprodução camponesa e transformação social. São Paulo: Marco Zero, 1989.

GARCIA, Marie France. O Bacurau: étude de cas d'un marché situé dans une usina. Dissertação (Mestrado em Antropologia). Museu Nacional do Rio de Janeiro. Programa de Pós-Graduação em Antropologia Social, 1977.

HUTCHINSON, Harry William. Village and plantation life in Northeastern Brazil. Seattle: University of Washington Press, 1957.

MELO, Mário Lacerda de. Paisagens do Nordeste em Pernambuco e Paraíba (guia da excursão n. 7, realizada por ocasião do XVIII Congresso Internacional de Geografia). Rio de Janeiro: Conselho Nacional de Geografia, 1958.

MIRANDA, Moema Maria Marques de. Espaço de honra e de guerra: etnografia de uma Junta Trabalhista. Dissertação (Mestrado). Rio de Janeiro: UERJ, 1991.

MONTENEGRO, Antônio Torres. O Trabalhador Rural nas Barras da Justiça do Trabalho (1964-1974). In: Territórios e Fronteiras (Online), v. 7, 2014.

PEREIRA, Clarisse Santos. A súmula 57 e as categorias de trabalho no campo: os trabalhadores rurais na Justiça do Trabalho (1979-1980). In: Tempos Históricos, v. 22, 2º sem. 2018. 
PRADO JÚNIOR, Caio. A questão agrária no Brasil. 2. ed. São Paulo: Brasiliense, 1979.

RAFFESTIN, Claude. Por uma geografia do poder. São Paulo: Ática, 1993, [1980].

ROGERS, Thomas D. As feridas mais profundas: uma história do trabalho e do ambiente do açúcar no Nordeste do Brasil. São Paulo: UNESP, 2017.

SANTOS, Milton. A Natureza do Espaço: Técnica e Tempo. Razão e Emoção [1996]. São Paulo: EDUSP, 2006.

SIGAUD, Lygia. A luta de classes em dois atos: notas sobre um ciclo de greves camponesas. In: Dados. v. 29, n. 3, 1986 .

SILVA, Fernando Teixeira da. “Justiça de Classe”: tribunais, trabalhadores rurais e memória. In: Revista Mundos do Trabalho, v. 4, n. 8, jul./dez. 2012.

SOUZA, Marcelo Lopes de. 'Território' da divergência (e da confusão): em torno das imprecisas fronteiras de um conceito fundamental. In: CASTRO, Iná Elias de; GOMES, Paulo Cesar da Costa; CORRÊA, Roberto Lobato (org.). Geografia: conceitos e temas. Rio de Janeiro: Bertrand Brasil, 2000.

VALVERDE, Orlando. O uso da terra no leste da Paraíba. In: Revista Brasileira de Geografia. Rio de Janeiro, v. 17, n. $1,1955$.

\section{Notas}

${ }^{1}$ Para citar alguns exemplos: Michel Cavassano Galvão, Processos de trabalhadores da agroindústria açucareira na Junta de Conciliação e Julgamento de Jaboatão de 1963 a 1965 (2010); Antônio Torres Montenegro, O Trabalhador Rural nas Barras da Justiça do Trabalho, 1964-1974 (2014); Christine Rufino Dabat, Uma 'caminhada penosa': a extensão do direito trabalhista à zona canavieira de Pernambuco (2008); Christine Rufino Dabat e Thomas D. Rogers, A peculiarity of labor in this region': workers' voices in the labor court archive at the Federal University of Pernambuco (2012) e Sugarcane Workers in Search of Justice: Rural Labour through the Lens of the State (2017) e Clarisse Santos Pereira, A súmula 57 e as categorias de trabalho no campo: os trabalhadores rurais na Justiça do Trabalho, 1979-1980 (2018).

${ }^{2}$ Sobre o conceito de território, Marcelo Lopes de Souza o define como “[...] espaço definido e delimitado por e a partir de relações de poder". Para ele, a questão primordial na definição do território “[...] não é, na realidade, quais são as características geoecológicas e os recursos naturais de uma certa área, o que se produz ou quem produz em um dado espaço, ou ainda quais as ligações afetivas e de identidade entre um grupo social e seu espaço..., mas o verdadeiro Leitmotiv é o seguinte: quem domina ou influencia e como domina ou influencia esse espaço?" (SOUZA, 2000).

${ }^{3}$ Vazio jurídico porque a CLT, em seu artigo $7^{\circ}$, excluía expressamente os trabalhadores rurais.

${ }^{4}$ Essa foi uma vitória, depois de uma grande greve, em 1963, do movimento dos trabalhadores rurais organizados, uma vez que a Tabela de Tarefas estipulava detalhadamente a área que deveria ser trabalhada em cada tipo de tarefa (sulcagem, cavagem e revolvimento da terra; plantio, limpa, adubação, corte e transporte da cana...), sempre considerando as variedades de cana, os tipos de solo e vegetação e a geografia do terreno que afetavam no esforço gasto na sua execução.

${ }^{5}$ Para mais detalhes sobre a complexidade acerca da ideia de distâncias na plantation, ver José Marcelo M. Ferreira Filho, Arquitetura espacial da plantation açucareira no nordeste do Brasil, Pernambuco, século XX (2020, no prelo).

${ }^{6}$ Segundo o Dicionário do açúcar, de Nelson Barbalho (1984, p. 389), Vale: “Tipo de ordem expressa em papel, para pagamento ou recebimento de qualquer quantia em dívida, o qual é passado sem forma legal, embora seja aceito livremente por todos quantos trabalham ou mantêm transações comerciais em usinas e engenhos de açúcar".

${ }^{7}$ Uma avaliação otimista dos efeitos do ETR e das Juntas pode ser encontrada em Fernando Teixeira da Silva, “Justiça de Classe": tribunais, trabalhadores rurais e memória (2012).

${ }^{8}$ Processo 04119/65. JCJ Escada. Josefa Bezerra de Lima vs Usina Massauassu/Eng. São Manoel. Arquivado pelo não comparecimento do reclamante à audiência.

${ }^{9}$ Processo 04416/65. JCJ Escada. José Onofre da Silva vs Destilaria Liberdade. Arquivado pelo não comparecimento do reclamante à audiência.

Recebido em: 29/04/2020

Aprovado em: 20/10/2020 